\title{
Spatial uncertainty analysis in coastal land use planning: a case study at Gold Coast, Australia
}

\author{
Razieh Mosadeghi $\uparrow$ Jan Warnken $\star$, Hamid Mirfenderesk $\infty$, Rodger Tomlinson $\uparrow$
}

$\dagger$ Griffith Centre for Coastal Management, $\ddagger$ Australian Rivers Institute, Griffith Griffith University, Parklands Dr., QLD University, Parklands Dr., QLD 4222, 4222, Australia

r.mosadeghi@griffith.edu.au r.tomlinson@griffith.edu.au Australia

j.warnken@griffith.edu.au $\infty$ Waterways and Flood Management, Gold Coast City Council, Nerang, QLD 4211, Australia hmirfenderesk@goldcoast.qld.gov.au

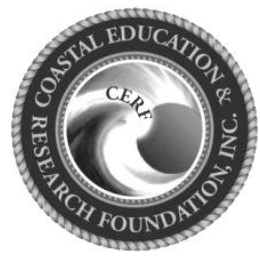

www.cerf-jcr.org

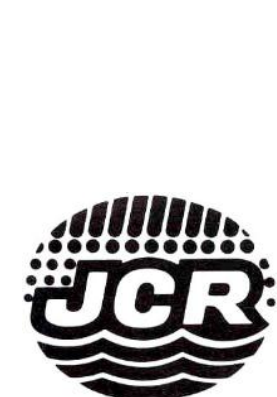

www.JCRonline.org

\section{ABSTRACT}

Mosadeghi, R., Warnken, J., Mirfenderesk, H., Tomlinson, R., 2013. Spatial uncertainty analysis in coastal land use planning: a case study at Gold Coast, Australia. In: Conley, D.C., Masselink, G., Russell, P.E. and O'Hare, T.J. (eds.), Proceedings $12^{\text {th }}$ International Coastal Symposium (Plymouth, England), Journal of Coastal Research, Special Issue No. 65, pp. 1003-1008, ISSN 0749-0208.

\begin{abstract}
Vulnerability of coastal areas to the global environmental changes and uncertainties in climate change predictions, particularly at local scales has presented a challenge to land-use planning in coastal cities. To make more accurate decisions, the uncertainty due to imperfect knowledge (epistemic uncertainty) is required to be considered in tandem with the inherent uncertainty or randomness of nature, and socio-economic dynamics (stochastic uncertainty). This paper examines the application of spatial Multi-criteria Decision Making (MCDM) tools to evaluate the effects of uncertainties at each stage of the decision- making process. The north east Gold Coast, Queensland (Australia) was considered as a case study to evaluate the sensitivity of the land-use planning decisions to input uncertainties. Uncertainty analysis in the framework of MCDM has been performed to address epistemic uncertainty. To examine the effects of uncertainty in a spatial context, conventional uncertainty analysis was combined with the visualisation capability of GIS and Monte Carlo simulation algorithm. The analysis results graphically display the sensitivity of output to the uncertainties in inputs and present a promising way to assist more transparency in the decision-making process.
\end{abstract}

\section{ADDITIONAL INDEX WORDS: Multi-criteria decision making, GIS, Monte Carlo simulation, sensitivity analysis.}

\section{INTRODUCTION}

Land-use planning decisions are generally undertaken under uncertainty. These uncertainties are due to the complexities of natural systems and human behavior, frequent lack of sufficient data, and at times, the politicised information (Refsgaard et al., 2007; Ascough et al., 2008; Zhang and Achari, 2010; Mosadeghi et al., 2012). On the other hand, land-use decisions affect different stakeholders who often have disparate views about the relevance and weights of decision criteria (Ascough et al., 2008; Zhang and Achari, 2010; Mosadeghi et al., 2012).

A large part of uncertainty in coastal areas is connected to lack of sufficient understanding of the coastal system (past, present, or future), the dynamic nature of the system and the interrelationships amongst its elements (Otter and Capobianco, 2000; Walker et al., 2003; Mosadeghi et al., 2012). Vulnerability of these ecosystems to global environment changes, and, uncertainty in climate change predictions, particularly at local scales impose additional levels of uncertainty into the decisionmaking procedure (Cowell and Zeng, 2003; Bruce, 2001). All these raise the need for explicit and systematic consideration of all potential uncertainties in the decision-making process (Cowell and

DOI: 10.2112/S165-170.1 received 07 December 2012; accepted 06 March 2013.

(C) Coastal Education \& Research Foundation 2013
Zeng, 2003; Bruce, 2001; Cowell et al., 2006).

In literature the uncertainty connected to lack of sufficient data is known as "model uncertainty" (Walker et al., 2003; Bruce, 2001; Refsgaard et al., 2007; Warmink et al., 2010). Other source of uncertainty is related to data that describe the coastal system, i.e. land use maps, the extent of coastal ecosystems and events, and climate data (input uncertainty) (Bruce, 2001, Mosadeghi et al., 2012).

In literature the concept of the uncertainty is also categorized based on the nature of uncertainty into:

- epistemic uncertainty- i.e. the uncertainty due to imperfect knowledge, which may be reduced by more precise data collection, additional monitoring and, using longer time series in modelling natural systems; and

- stochastic uncertainty- as the inherent uncertainty or randomness of nature, human behavior and social, economic, and cultural dynamics. No matter how precise the data collection is and for how long historical data time series exist, there will always be some uncertainty related to the chaotic nature of natural phenomena, such as relative sea level changes and frequency and severity of storms (Otter and Capobianco, 2000; Walker et al., 2003; Refsgaard et al., 2007; Mosadeghi et al., 2012). 
In coastal land-use planning spatial data are to be incorporated into coastal models and this will result in an additional dimension to uncertainty, known as "spatial uncertainty". Spatial uncertainty can manifest itself as input uncertainty driven by inaccurate (epistemic uncertainty) or fuzzy (unexplainable randomness stochastic uncertainty) boundaries, point locations or extent of spatial features (Bruce, 2001; Mosadeghi et al., 2012). Inevitably, this uncertainty will have influence on the extent of the location(s) where the land-use options are defined. It also can affect the prioritisation of land-use options being selected throughout the decision-making.

The ubiquitous nature of uncertainty in decision-making procedure and vulnerability of coastal systems highlights the need to examine and quantify the effects of uncertainty on coastal landuse model outputs (Otter and Capobianco, 2000; Bruce, 2001).

In the last decade, considerable resources have been allocated towards improving the accuracy of physical models that are capable of simulating and projecting hydrological, atmospheric and ecological processes (Webster, et al.,2003; Refsgaard et al., 2007; Teegavarapu, 2010), resulting in substantial reduction associated with model uncertainties ( Refsgaard et al., 2007). Others have attempted to address model uncertainty by combining visualisation capability of GIS with new decision-making tools such as Multi-criteria decision making (MCDM), tying uncertainty analyses into the decision-making framework (Schluter and Ruger, 2007; Bryan and Crossman, 2008; Lesslie et al., 2008; Chen et al., 2010; Chen et al., 2011).

The case study approach in this paper investigates how the uncertainty in the inputs of a coastal land-use planning model affects the selection of development alternatives. The extent of uncertainty in the spatial distribution pattern of options is evaluated to visually display the effects of spatial uncertainty.

\section{METHODS}

The study area is located in the northeast Gold Coast, south-east Queensland (QLD), Australia, occupying an area of 17,500 ha. This area is bordered by the Logan River to the north, the Pacific Motorway (M1) to the west, the boundary of the urban footprint in the vicinity of Yawalpah Road and McCoys Creek to the south and southern Moreton Bay to the east.

A comprehensive investigation of environmental conditions and development constraints was undertaken to address the potentials and limitations of lands with a particular natural features to accommodate a specific type or intensity of development. The study area includes some significant natural areas such as Pimpama River Conservation Area; McCoys Creek catchment; Coomera-Pimpama Koala Conservation Area; tidal wetlands; significant coastal wetlands; and areas of QLD state biodiversity significance.

The land suitability criteria were established based on literature review, existing regional and local planning instruments (e.g. SEQ Regional Plan and Gold Coast Planning Scheme), and available datasets. These criteria covered the environmental constraints and the necessary infrastructure for future developments and were identified for four land use categories, i.e. (i) Residential; (ii) Recreational; (iii) Extractive industry; and (iv) Marine industry. It should be noted that this land use classification is based on the clarification in the SEQ Regional Plan that the majority of the study area is not intended for urban development purposes (Queensland Government, 2009).

\section{Multi-criteria Decision Making}

MCDM techniques apply structured mechanisms and algorithms for identifying the most suitable solution for a multitude of facts, values and perceptions of stakeholders. Multicriteria decision making involves a multi-stage process of defining objectives, choosing the criteria to measure the objectives, specifying alternatives, assigning weights to the criteria, applying the appropriate mathematical algorithm for ranking alternatives and choosing the best alternative (Herath and Prato, 2006; Ananda and Herath, 2009; Mosadeghi et al., 2009).

In principle, these techniques try to overcome uncertainties by allowing sensitivity and uncertainty analyses to improve knowledge integration across environmental, physical and social sciences (Hyde et al., 2005; Herath and Prato, 2006; Bryan and Crossman, 2008; Lai et al., 2008; Hajkowicz, 2009). Interest in quantifying spatial uncertainty has increased developing MCDMmodels that tie uncertainty analyses into the visualisation capability of GIS (see Schluter and Ruger, 2007; Chen et al., 2011). These methods graphically display the output uncertainty based on the input uncertainty, thereby presenting the spatial dimensions of uncertainties (Chen, et al., 2011).

The analytic hierarchy process (AHP) is most commonly applied MCDM technique (Herath and Prato, 2006; Taslicali and Ercan, 2006; Ananda and Herath, 2009; Chen et al., 2010). The AHP was created by Thomas Satty in the late 1960 s to select the best from a number of alternatives with respect to several criteria. It emerged as a reaction to the finding that there was a lack of common, easily understood and easy-to-implement methodology to enable making complex decisions (Kristof, 2005). It allows group decision-making, where the knowledge, values, and experience of all group members can be used in the model (Chang et al., 2008). The widespread use of AHP is due to its simplicity, ease of use and great flexibility in integrating with other decision making techniques (Kristof, 2005; Ananda and Herath, 2009).

The spatial AHP suitability procedure integrates MCDM with the spatial capability of GIS. Integration of AHP and GIS has become popular because of its capacity to integrate a large amount of heterogeneous data and the ease in obtaining the weights of a large number of criteria (Chen et al., 2010).

The MCDM process requires selected participants to rank the criteria based on pairwise comparisons. In this study, these comparisons were designed as a survey. Thirty-five questionnaires were distributed among a variety of experts including members of Gold Coast City Council Planning, Environment and Transport Directorate as well as academic experts at national and local levels. Each participant was asked to rank the criteria and subcriteria by referring to the numerical scale of $1-9$, with a score of 1 representing indifference between the two criteria and 9 representing absolute importance. Fourteen responses were received (40\% response rate). Then, the data for pairwise comparisons were analysed using MATLAB ${ }^{\circledR}$ scripting based on AHP algorithms to obtain the final ranking for each criterion. The analysis was carried out using aggregated individual preferences, which were calculated based on geometric means of individual experts' ratings for each criterion. The geometric mean is consistent and upholds separability, unanimity and homogeneity which have to be satisfied to aggregate individual judgements (Ananda and Herath, 2008). The Consistency Ratio (CR) was calculated by:

$$
C R=C I / R I(n)
$$

Where $\mathrm{CI}$ is the consistency index given by:

$$
C I=\left(\lambda_{\max }-n\right) /(n-1)
$$

$R I(n)$ is the random consistency index for matrices of order $n$ and $\lambda_{\max }$ is the principal eigenvalue of the judgement matrix. 
In this study a standard CR threshold value of 0.10 was applied, i.e., if $\mathrm{CR}<0.10$, the pairwise comparison matrix is consistent and the weight values are valid (Saaty and Vargas, 2001; Ananda and Herath, 2008; Kordi and Brandt, 2012). The pairwise comparisons in this study were consistent with the overall mean consistency ratio (CR) for all four categories of $<0.005$.

After computing the priority weights for each criterion, the weights were multiplied by their respective raster GIS layer. A weighted linear combination equation $L S=\sum_{i=1}^{n} W_{i} \quad$ was formulated and used to combine layers and derive a final suitability map. When LS is the suitability for particular land-use;

$n$ is the number of evaluated criteria and $w_{i}$ is the weight of each criterion.

The five utilized suitability classes were based on the assigned weights for each pixel after applying the overlay function to the weighted criterion maps. The resultant maps show spatial patterns and distributions of the most suitable land for further development. The cut-off values for suitability classes were identified based on the fundamental scale of AHP (1-9). The five suitability classes for categorizing the results were defined as: (S1) highly suitable cells with weights higher than 7; (S2) suitable cells with weights between 6 and 7; (S3) moderately suitable cells with weights between 5 and; (S4) marginally suitable cells with weights between 4 and 5; and $(\mathrm{N})$ unsuitable cells with weights less than 4. The final suitability maps were reclassified in ArcGIS based upon the five suitability classes; and then were converted to polygon feature classes for further analysis.

\section{Uncertainty Analysis}

The purpose of uncertainty analysis is to describe and quantify the risk in selecting a specific planning option (Chen et al., 2011) In other words, it measures how robust the choice of an option is to changes in the inputs of a model (Otter and Capobianco, 2000; Bruce, 2001; Ananda and Herath, 2008; Chen et al. 2009; Steele et al. 2009; Chen et al., 2011).

Sensitivity analysis is a commonly used tool for evaluating uncertainty in the models (Otter and Capobianco, 2000; Walker et al., 2003; Bruce, 2001; Refsgaard et al., 2007; Bryan and Crossman, 2008; Chen et al., 2010; Chen et al., 2011; Mosadeghi et al., 2012).

Several sensitivity analysis techniques are available in the literature. Saltelli et al. (2000) group sensitivity analysis methods into three classes: screening methods, local SA methods and global SA methods. Screening methods can be used when dealing with models that have a large number of input parameters but with only a few of the input parameters having a significant effect on the model output (Saltelli et al., 2000). Local SA concentrates on the local impact of the factors on the model.

These methods however, are less helpful when SA is used to compare the effect of various factors on the output (Saltelli et al., 2000; Morio, 2011). Global SA techniques incorporate the influence of the whole range of variations and the form of the probability density function of the inputs.

It is suggested when various input variables are affected by uncertainties of different orders of magnitude, a global SA method should be used (Saltelli et al., 2000; Morio, 2011).

To address the impact of uncertainty on various criteria weights, a global SA, namely Monte Carlo analysis, is used in this study.

Monte Carlo analysis is based on performing multiple evaluations with randomly selected model inputs, then using the results of these evaluations to determine both uncertainty in model predictions and apportioning the contribution of each factor to the uncertainty (Otter and Capobianco, 2000; Saltelli et al., 2000; Liu et al., 2010; Chen et al., 2011; Madani and Lund, 2011). Saltelli et al. (2000) define five steps for the Monte Carlo uncertainty analysis as follows:

- the selection of ranges and distributions for each input variable;

- generation of a sample from the ranges and distributions specified in the first step;

- evaluation of the model for each element of the sample;

- uncertainty analysis;

- sensitivity analysis.

In the first step, in the absence of information about ranges and distributions for the input variables, a crude characterization may be adequate, especially if the analysis is primarily exploratory. Uniform or log-uniform distributions may be assumed and physical plausibility arguments might be used to establish the ranges. Sensitivity analysis results generally depend more on the selected ranges than on the assigned distributions (Saltelli et al., 2000).

The second step in the Monte Carlo analysis involves the selection of a sample from the distributions developed in the first step. The most common sampling methods are: random sampling; stratified sampling (including Latin hypercube sampling); and quasi-random sampling. Random sampling has been applied in this study. In this sampling method, a sample $\left(x_{1}, x_{2}, \ldots, x_{N}\right)$ of the desired dimension $N$ is generated from the joint distribution of the input variables or, when these are independent, from their marginal distributions. From the statistical point of view, random sampling has advantages, since it produces unbiased estimates of the mean and variance of the variable of interest, $Y$ (Saltelli et al., 2000).

The third step in a Monte Carlo analysis is the evaluation of the model for each of the sample elements. In this step each element is supplied to the model as an input, creating a sequence of results of the form $y_{i}=f\left(x_{i}\right), i=1, \ldots, N$, to be used in the uncertainty and sensitivity analysis. In the fourth step of the Monte Carlo uncertainty analysis, the expected value and variance for the output variable " $y$ " are estimated by (Saltelli et al., 2000):

$$
\begin{aligned}
& \hat{E}(Y)=\frac{1}{N} \sum_{i=1}^{N} y_{i} \\
& \hat{V}(Y)=\frac{1}{N-1} \sum_{i=1}^{N}\left[y_{i}-E \hat{(Y)}\right]^{2}
\end{aligned}
$$

The final step in this procedure is sensitivity analysis to evaluate the contribution of the different sources of variation in the system (Saltelli et al., 2000). Many techniques can be used to measure sensitivity including scatterplots, correlation coefficients, and regression analyses.

In this study, correlation coefficients were applied as a simple and straightforward technique. This approach is the usual linear correlation coefficient computed on the points $\left(x_{i j}, y_{i}\right), i=1, \ldots, N$.

The correlation $r_{x_{i} y}$ between the input variable $X_{j}$ and the output $Y$ is defined by (Saltelli et al., 2000): 


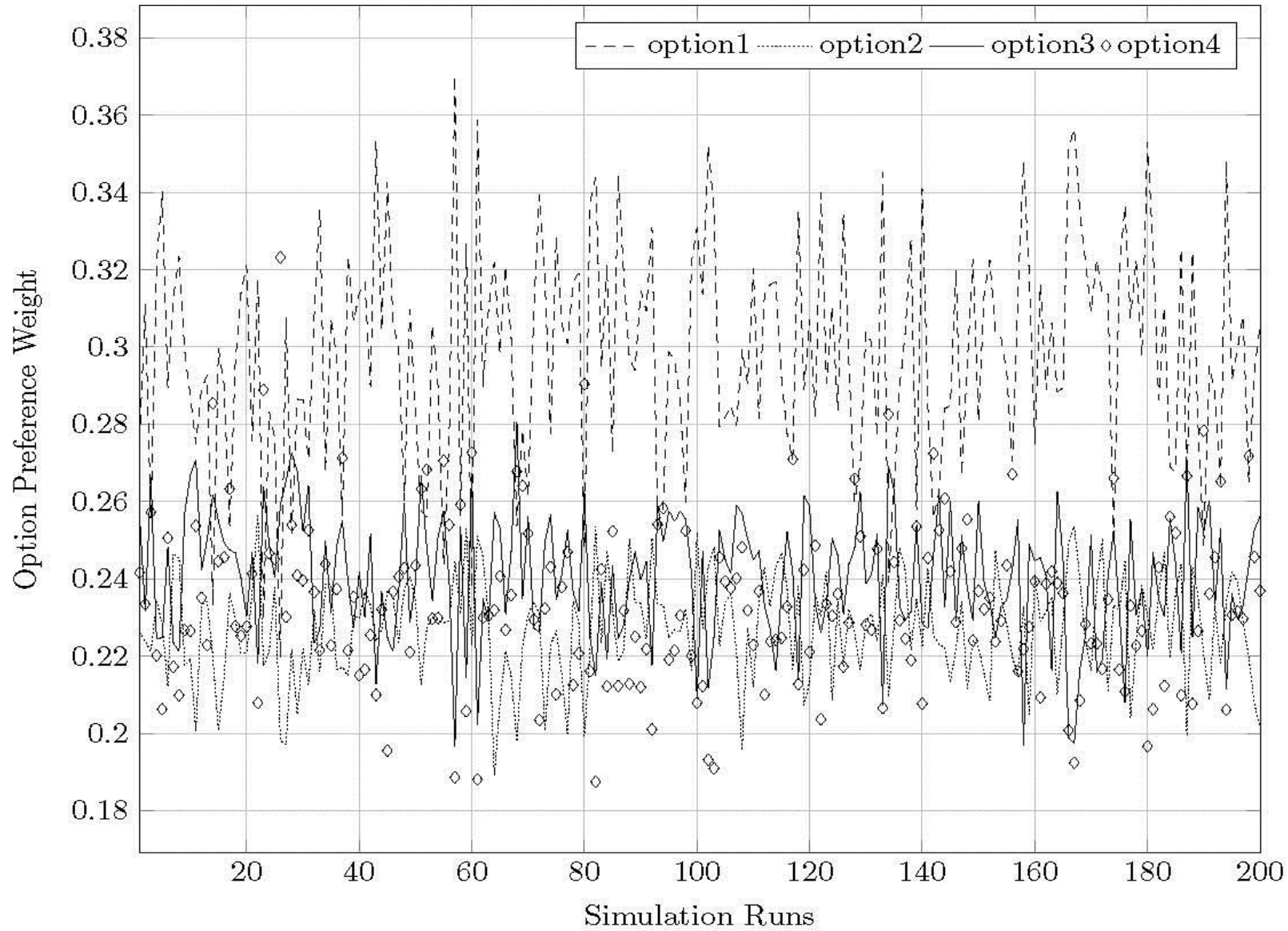

Figure 1 Uncertainty analysis results in the residential category.

$$
r_{x_{i} y}=\frac{\sum_{i=1}^{N}\left(x_{i j}-\bar{x}_{j}\right)\left(y_{i}-\bar{y}\right)}{\left[\sum_{i=1}^{N}\left(x_{i j}-\bar{x}_{j}\right)^{2}\right]^{1 / 2}\left[\sum_{i=1}^{N}\left(y_{i}-\bar{y}\right)^{2}\right]^{1 / 2}}
$$

Where $\bar{y}=\sum_{i} \frac{y_{i}}{N}, \bar{x}_{j}=\sum_{i} \frac{x_{i j}}{N}$.

The coefficient $r_{x_{i} y}$ provides a measure of the linear relationship between $X_{j}$ and $Y$ (Saltelli et al., 2000).

Accordingly, in this research Monte Carlo uncertainty and sensitivity analysis were performed to evaluate the robustness of outcomes and to determine the probability of changes in rank ordering. The final weights for the different criteria provided by the experts were varied within a range of $5 \%, 10 \%$, and $20 \%$ (percentage of uncertainty). Then, using random sampling, the probability of obtaining different option rankings was calculated. Figure 1 summarizes the results from the 200 simulations and compares the stability of the options for residential and extractive industry.

In addition to evaluating the effects of uncertainty on option ranking orders, the extent of uncertainty in the spatial distribution patterns of options was also evaluated. This enabled us to graphically display the output uncertainty based on the input uncertainty and therefore present spatial dimensions of uncertainties. Therefore, an uncertainty level of \pm 20 was applied to evaluate the impacts of criteria weights changes on the spatial pattern of the evaluation maps. The original criteria weights from the AHP model were manipulated with a range of $\pm 20 \%$. The generated weights for each criterion were then applied in the GIS overlay process by using Raster Calculator.

\section{RESULTS}

The first stage of uncertainty analysis shows how robust the choice of an area (alternative) for the future development is to changes in the inputs of the model. The results showed in the case of 5\% uncertainty, the preference weight of options hardly vary. Once, uncertainties were increased to $10 \%$ and $20 \%$, different rankings were observed in some cases. For example, although option 1 remained the most suitable option in the majority of the simulation runs in the residential category, it was difficult to distinguish the preference order for the other options. This situation was particularly significant when uncertainty increased to $20 \%$. Figure 1 illustrates how option 1 is the best alternative for future residential developments compare to other alternatives. However, the graph shows by considering different level of uncertainty this preference would vary. For example the results of simulation 25 show how option 4 becomes the most suitable alternative instead of option 1 .

As the second stage of uncertainty analysis, spatial uncertainty was investigated. At this stage we examined whether the changes in criteria weights (inputs) would affect the spatial extent of the suitability classes (i.e. S1, S2, S3, S4, and N). Table 1 summarises the spatial changes of suitability classes while considering $20 \%$ uncertainty in the inputs. In the residential category, the $20 \%$ change in the criteria weights caused a significant suitability class modification. The most sensitive class was $\mathrm{N}$, when the uncertainty analysis showed a $98 \%$ decrease in the allocated area 


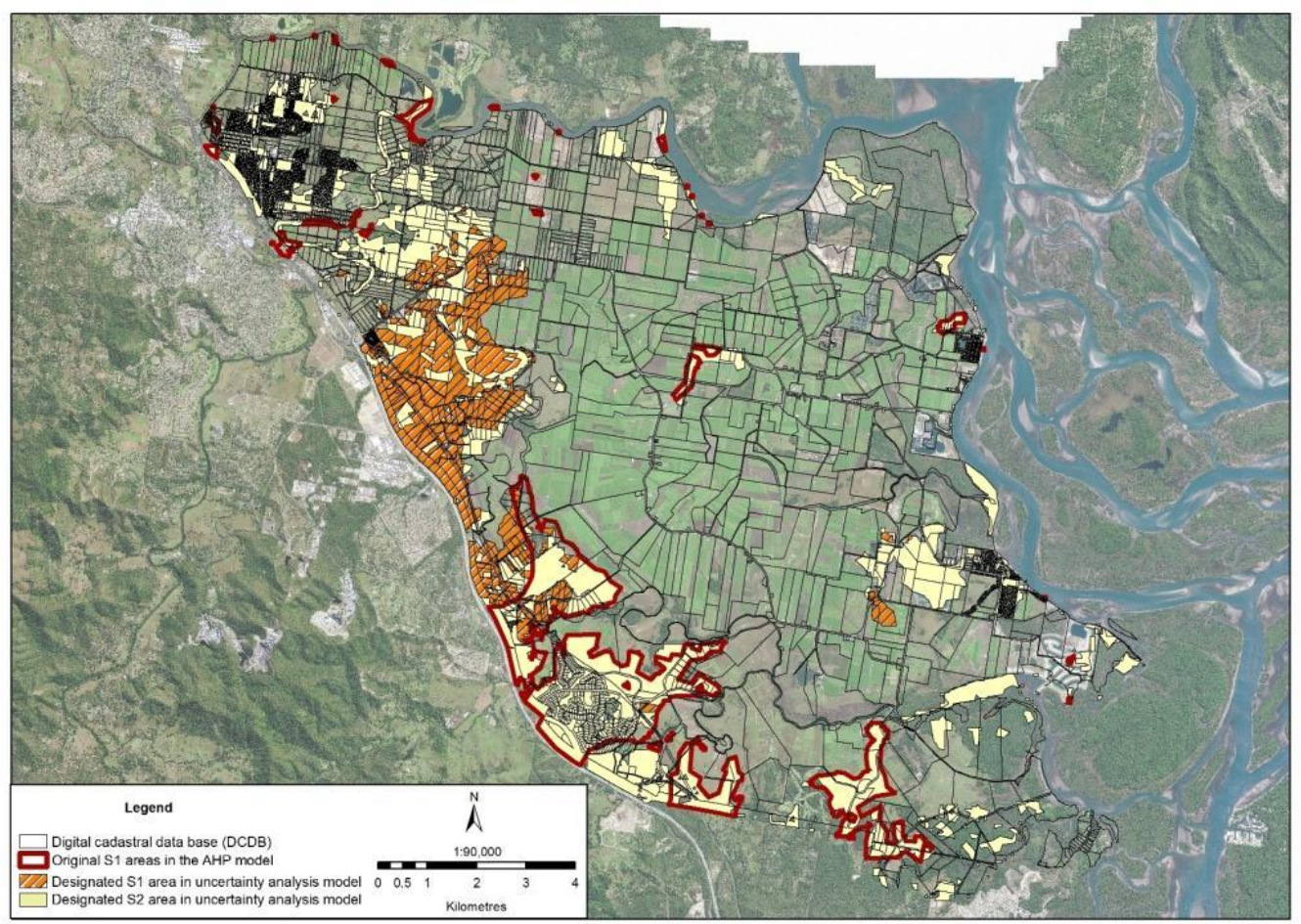

Figure 2. Spatial uncertainty analysis for the residential category

for this class. The least sensitive class was S3 with a $16 \%$ difference. Spatial uncertainty evaluation depicted a decline in the area of S1. Further evaluation showed that the majority area of S1 in the evaluation models was reclassified as $\mathrm{S} 2$ in the uncertainty models. In the extractive and marine industries, $20 \%$ criteria weight changes did not cause significant differences in the spatial distribution of the most suitable class (in this case S3).

This means that these two categories are less sensitive to the spatial uncertainties due to changes in the possible criteria weights. There was a significant increase in the level of suitability in the model, with a $100 \%$ increase in the allocated area for S1 and S2.

Within the marine category, the spatial pattern of the most suitable areas did not change significantly, while there was little difference in the area of suitability classes.

In the recreation category criteria weights changes caused significant suitability class modification. In this category, the trend was toward increasing the area of high suitability and decreasing the area of low suitability. The model was significantly sensitive with a $100 \%$ increase in the area of S1 and a $100 \%$ decrease in the area allocated for class $\mathrm{N}$.

Figure 2 shows how applying $20 \%$ uncertainty has shifted the extent of most suitable alternative for residential development. It illustrates that most of the areas identified as highly suitable (class S1) has been downgraded to suitable area (class S2). Applying $20 \%$ uncertainty has also shifted the highly suitable areas (S1, hatched area on the map) further to the northern part of the study area.

\section{DISCUSSION AND CONCLUSION}

The results of this study highlight the importance of analysing uncertainty and sensitivity, as different decision-making methods have different levels of stability and robustness of their preferred options. The study results show how the ranking order of the best
Table1. The impacts of criteria weights changes on the area of each suitability class

\begin{tabular}{|c|c|c|c|c|c|}
\hline & \multicolumn{2}{|c|}{ Residential } & \multirow{2}{*}{$\begin{array}{l}\text { Extractive } \\
\\
100 \\
59.80 \\
7.51 \\
-13.66 \\
-78.37\end{array}$} & \multirow{2}{*}{$\begin{array}{l}\text { Marine } \\
0 \\
0 \\
39.62 \\
8.00 \\
-14.66\end{array}$} & \multirow{2}{*}{$\begin{array}{l}\text { Recreatio } \\
100 \\
93.57 \\
-41.50 \\
-92.76 \\
-100\end{array}$} \\
\hline $\begin{array}{l}\text { Area } \\
\text { changes in } \\
\text { evaluation } \\
\text { maps \% }\end{array}$ & $\begin{array}{l}S 1 \\
S 2 \\
S 3 \\
S 4 \\
N\end{array}$ & $\begin{array}{l}-23.77 \\
-43.03 \\
16.08 \\
41.03 \\
-98.98\end{array}$ & & & \\
\hline $\begin{array}{l}\text { Most suitable } \\
\text { area in origin } \\
\text { maps }\left(\mathbf{k m}^{2}\right)\end{array}$ & & $\begin{array}{l}\text { S1: } \\
13.80\end{array}$ & S2: 11.63 & S3: 7.85 & S2:5.94 \\
\hline \multicolumn{2}{|c|}{$\begin{array}{l}\text { Most suitable } \\
\text { area in } \\
\text { uncertainty } \\
\text { evaluation maps } \\
\left(\mathbf{k m}^{2}\right)\end{array}$} & $\begin{array}{c}\text { S1: } \\
10.52 \\
\text { S2: } \\
29.93\end{array}$ & $\begin{array}{c}\text { S1: } 5.00 \\
\text { S2: } 28.93\end{array}$ & S3: 13 & S1: 7.21 \\
\hline $\begin{array}{l}\text { Spatial } \\
\text { Intersection } \\
\text { area }\left(\mathbf{k m}^{2}\right)\end{array}$ & & 11.45 & 11.51 & 7.27 & 4.76 \\
\hline
\end{tabular}

suggested option can vary when different levels of uncertainty are deployed into a decision making model. In addition, the results of spatial uncertainty analysis demonstrated that uncertainty not only affects the selection of the best option, but also can affect the spatial extent of the preferred option. The sensitivity of the results to the changes of the inputs could be because decision makers (participants in the questionnaire) might not be completely aware of their preferences regarding the suitability criteria. This could be due to the complexity of coastal ecosystems. Spatial uncertainty analysis undertaken in this study demonstrated the effects of uncertainty in the spatial data (including accuracy, reliability, precision, error) on the extent of the preferred alternative. Wherever possible, these sources of uncertainty should be 
eliminated through better data collection, group decision-making and engaging different stakeholders during the decision-making process. It is evident that not all uncertainties, particularly uncertainties due to the unpredictable nature of the natural systems, can be eliminated. However, uncertainty analysis must be performed and a clear description of the sensitivity of the final decisions to the input variables should be made from the onset of the decision-making.

\section{ACKNOWLEDGEMENT}

The work described in this publication was performed as part of a PhD research at Griffith Centre for Coastal Management and supported by Gold Coast City Council.

\section{LITERATURE CITED}

Ananda, J. and Herath G., 2009. A critical review of multi-criteria decision making methods with special reference to forest management and planning. Ecological Economics, 68 (10), 2535-2548.

Ascough, J.C., Maier, H.R., Ravalico, J.K. and Strudly, M.W., 2008. Future research challenges for incorporation of uncertainty in enviornmental and ecological decision-making. Ecological Modelling, 219 (3-4), 383-399.

Bruce, E., 2001.Spatial uncertainty in marine and coastal GIS. In Bartlett, D. and Smith, J. (eds), GIS for coastal zone management. Florida, US:CRC press, 51-62.

Bryan, B. A. and Crossman N. D., 2008. Systematic regional planning for multiple objective natural resource management. Journal of Environmental Management, 88 (4), 1175-1189.

Chen, H., Wood, M.D, Linstead, C., and Maltby, E., 2011. Uncertainty analysis in a GIS-based multi-criteria analysis tool for river catchment management. Environmental Modelling \& Software, 26 (4), 395-405.

Chen, Y., Yu, J., and Khan, S., 2010. Spatial sensitivity analysis of multi-criteria weights in GIS-based land suitability evaluation. Environmental Modelling \& Software, 25(12), 1582-1591

Cowell, P and Zeng, T.Q., 2003. Integrating uncertainty theories with GIS for modeling coastal hazards of climate change. Marine Geodesy, 26, 5-18.

Cowell, P.J., Thom, B.G., Jones, R.A., Everts, C.H., and Simanovic, D., 2006. Management of uncertainty in predicting climate change impacts on beaches. Journal of Coastal Research, 22(1), 232-245.

Dorini, G., Kapelan, Z. and Azapagic, A., 2011. Managing uncertainty in multiple-criteria decision making related to sustainability assessment. Clean Technology and Environmental Policy, 13 (1), 133-139.

Herath, G., Prato T., 2006. Using Multi-criteria decision analysis in natural resource management, Burlington: Ashgate publisher.

Hyde, K.M., Maier, H.R., and Colby, C.B., 2005. A distancebased uncertainty analysis approach to multi-criteria decision analysis for water resource decision making. Journal of Environmental Management, 77(4), 278-290.

Kordi, M. and Brandt, S.A., 2012. Effects of increasing fuzziness on analytic hierarchy process for spatial multicriteria decision analysis. Computers, Environment and Urban Systems, 36(1), 43-53.

Kristof, G. M., 2005. Planning Business Improvement Using Analytic Hierarchy Process and Design structure Matrix. Thesis (Master). Montana State University.
Lesslie, R.G., Hill, M.J., Hill, P., Cresswell, H.P., and Dawson, S., 2008. The Application of a Simple Spatial Multi-Criteria Analysis Shell to Natural Resource Management Decision Making. In: C. Pettit, W. Cartwright, I. Bishopet, eds., Berlin Landscape Analysis and Visualisation:Spatial Models for Natural Resource Management and Planning. Springer, 73-96.

Liu, Y., Chen, J., He, W., Tong, Q., and Li, W., 2010. Application of an uncertainty analysis approach to strategic environmental assessment for urban planning. Environmental Science and Technology, 44, 3136-3141.

Morio, J., 2012. Global and local sensitivity analysis methods for a physical system. European Journal of Physics, 32(6), 15771586.

Mosadeghi, R., Tomlinson R., Mirfenderesk, H., and Warnken, J., 2009. Coastal Management Issues in Queensland and Application of the Multi-Criteria Decision Making Techniques. Journal of coastal research, SI56, 1252-1256.

Mosadeghi, R., Warnken, J., Tomlinson, R., and Mirfenderesk, H., 2012. Uncertainty analysis in the application of multi-criteria decision making methods in Australian strategic environmental decisions. Journal of Environmental Planning and Management, DOI:10.1080/09640568.2012.717886.

Otter, H. and Capobianco, M., 2000. Uncertainty in integrated coastal zone management. Journal of Coastal Conservation,6, 23-32.

Refsgaard, J.C., van der Sluijs, J.P., Lajer Højberg, A., and Vanrolleghem, P.A., 2007. Uncertainty in the environmental modelling process A framework and guidance. Environmental Modelling \& Software, 22 (11), 1543-1556.

Saltellie, A. Chan, K., \& Scott, E.M., 2000. Sensitivity Analysis. England: John Wiley \& Sons, Ltd. 467P.

Schluter, M. and Ruger, N., 2007. Application of a GIS-based simulation tool to illustrate implications of uncertainties for water management in the Amudarya river delta. Environmental Modelling \& Software, 22 (2), 158-166.

Taslicali, A.K and Ercan, S., 2006. The analytic hierarchy \& the analytic network processes in multi-criteria decision making: a comparative study. Journal of Aeronautics and Space Technologies, 2 (4), 55-65.

Walker, W.E., Harremoe"s, P., Rotmans, J., Van der Sluijs, J.P., Van Asselt, M.B.A., Janssen, P., Krayer, V., and Krauss, M.P., 2003. Defining uncertainty a conceptual basis for uncertainty management in model-based decision support. Integrated Assessment, 4 (1), 5-17.

Teegavarapu, R.S.V., 2010. Modeling climate change uncertainties in water resources management models. Environmental Modelling \& Software, 25(10), 1261-1265.

Warmink, J.J., Janssen, J.A.E.B., Booij, M.J., and Krol, M.S., 2010. Identification and classification of uncertainties in the application of environmental models. Environmental Modelling \& Software, 25 (2), 1518-1527.

Webster, M., Forest, C., Reilly, J., Babiker, M., Kicklighter, D., Mayer, M., Prinn, R., Sarofim, M., Sokolov, A., Stone, P., and Wang, C., 2003. Uncertainty Analysis of Climate Change and Policy Response. Climatic change, 61(3), 295-320.

Zhang, K. and Achari, G., 2010. Uncertainty propagation in environmental decision-making, using random sets. Procedia Environmental Sciences, 2, 576-584. 